\title{
Urban and Rural Airborne Particulate Matter: Seasonal Variation of Alpha Activity in Kanyakumari District
}

\author{
C. Jesu Raj† and J. Prema Kumari \\ Department of Chemistry, Scott Christian College (Autonomous), Nagercoil, Manonmaniam Sundaranar University, \\ Tirunelveli, India \\ $\dagger$ Corresponding author: C. Jesu Raj; jesuraj.jpp@gmail.com
}

Nat. Env. \& Poll. Tech.

Website: www.neptjournal.com

Received: 24-08-2020

Revised: $01-10-2020$

Accepted: 16-10-2020

Key Words:

Airborne particulate matter

Alpha counter

Alpha activity

Kanyakumari district

\begin{abstract}
All forms of life on earth including man have evolved in the presence of radiation and have always been exposed to them from the natural environment. The health effect from exposure to alpha particles depends greatly on how a person is exposed. If alpha-emitters are inhaled, swallowed, or get into the body through a cut, the alpha particles can damage sensitive living tissue. In this paper, investigations have been made to determine the presence of alpha activity in the air. Hence, the alpha activity was measured by collecting Airborne Particulate Matter (APM) non-simultaneously on Whatman filters from ten sampling sites in Kanyakumari District during the summer and winter seasons using a high volume sampling method. The sampling sites are characterized by different contributions from ore refining factories like Indian Rare Earths (IRE) Limited, mountain areas, some industrial, non-nuclear activities like tiles and brick factories in and around the Kanyakumari district. The alpha activity in airborne particulate matter collected was determined by Alpha Counter and their results were tabulated.
\end{abstract}

\section{INTRODUCTION}

Alpha particles come from the decay of the heaviest radioactive elements, such as uranium, radium, and polonium. Even though alpha particles are very energetic, they are so heavy that they use up their energy over short distances and are unable to travel very far from the atom. Alpha particles lack the energy to penetrate even the outer layer of skin, so exposure to the outside of the body is not a major concern (Songul et al. 2012). Radioactivity in the atmosphere originates from naturally radioactive material, cosmogenic production, nuclear weapons testing, and nuclear accidents (Arkian et al. 2007, Nakpil et al. 2019).

Alpha radiation is an average of about 20 times more dangerous, and in experiments with inhaled alpha emitters, up to 1000 times more dangerous than an equivalent activity of beta-emitting or gamma-emitting radioisotopes. An increase in the background ionization radiation from numerous sources has various health side effects on the populace (Avwiri \& Go 2006).

Sources and levels of air pollution can vary from place to place. In urban areas, different kinds of motor vehicles, industries, and other commercial activities may cause air pollution. In rural areas, air pollution is caused by the use of wood, crop residues, and dung cakes as fuel for domestic purposes and the dust generated from unpaved roads (Roy \& Adhikari 2009).

The activity of natural ionization sources such as soil, rocks, outer space nuclides, and radiation is a determinant factor for air ion concentration in a particular place (Samotaev \& Nikolay 2015).

The interaction between humans and the environment has resulted in variation in the quantity and quality of the background radiation to which human beings are exposed. It is virtually impossible for people to avoid radiation from their living environment. Therefore, it is necessary to keep a constant vigil on the changes caused by the various sources of ionizing radiation exposures. For these reasons, the examination of alpha activity and trace elements concentration size distribution is a useful tool for the characterization and apportionment of the sources of rural and urban airborne particulate matter.

The Kanyakumari district is recognized as the area with the highest level of air pollution. This is because in a relatively small area of $1684 \mathrm{~km}^{2}$ the district has a dense population (over 1.8 crores inhabitants). Indian Rare Earths (IRE) Limited, Cashew nut factories, Tiles and brick factories are the industrial sources in Kanyakumari District. The present research focused on the presence of alpha activity in ambient 
particulate matter. The comparison of the results obtained for ten sites in the district in diverse periods of the year allows appraisal of the input of different pollution sources in the district. The aim of this study is the identification and assessment of gross alpha radioactivity levels in air-suspended particulate matter in and around the Kanyakumari District.

\section{MATERIALS AND METHODS}

A high-volume air sampler running on electrical energy has been purchased to collect air samples contaminated with automobile exhaust at the above-mentioned sampling sites. The extent of absorption of heavy metals in each sample is calculated and correlated with the results obtained earlier. The suspended particles of air are retained in the filter. With the help of a blower, the duration of sampling is measured in an elapsed time meter which is placed in series. The sampler was placed $2 \mathrm{~m}$ above the ground level. Each sampling lasted to minimize the influence of short-term weather condition changes.

For measuring the presence of alpha activity in the air, the radiation counting system (Nucleonix RC 605A) is used with an alpha counter of $\mathrm{ZnS}(\mathrm{Ag})$ solid scintillation detector. A punched filter paper of size $2.5 \mathrm{~cm}$ diameter was inserted into the alpha counter. The alpha activity calculation was corrected for the mass thickness of the aerosol deposit collected in the filters. The background of the detector was determined with measurements that routine samples were counted and was measured using clean filters. The average detection limit for this apparatus was approximately $0.3 \pm$ $0.1 \mathrm{mBq} \cdot \mathrm{m}^{-3}$ background activities for alpha. A background subtraction procedure was applied to each of the gross alpha analyses. For each measurement of alpha emitters in the filters, counting times of $5 \mathrm{~h}$ were used.

Gross measurements are used as a method to screen samples for relative levels of radioactivity in the air. It is simply a measurement of all alpha activity present, regardless of specific radionuclide source. The samples were counted for gross alpha radioactivity using a low background multiple detector gas flow proportional counter. Alpha emitter radionuclides are listed below:

- Americium-241

- Plutonium-239

- Uranium-238

- Thorium-232

- Radium-226

- Radon-222

- Polonium-210
Equation (1) used to calculate the alpha radioactivity is given below:

$$
\alpha \text { Activity }=\frac{N}{T} * \frac{100}{E} * \mathrm{P} * \frac{1}{V * 8 * 60}
$$

Where $\mathrm{N}$ is the net alpha count rate (gross alpha count rate minus the background count rate) at the alpha voltage plateau; $\mathrm{E}$ is the efficiency of the alpha counter; $\mathrm{P}$ is a paper factor; $\mathrm{V}$ is the volume of air in the sample.

\section{SAMPLING LOCATION}

The samples were taken in diverse periods in the years 20142016 non-simultaneously at ten measuring points to analyze the influence of traffic intensity and other sources on ambient air pollution. Fig. 1 shows the six sampling points from the urban areas and four sampling points from the rural areas of the Kanyakumari district. The sampling locations of the Kanyakumari district were characterized by dense buildings, narrow streets and heavy traffic, local combustion, high wind, and seashore with dense buildings, factories like cashew nut factory, ore refining factory, tiles, and brick factories, and agriculture specialization. All these factors contribute to gross alpha radioactivity levels, especially in the winter period.

The samples were taken by placing the high volume air sampler at $1 \mathrm{~m}$ above the ground at the following urban locations:

- Kaliyakkavilai - Dense buildings, narrow streets, and heavy traffic and are available in between the border of Tamilnadu and Kerala.

- Marthandam - Intensive traffic and dense population.

- Thuckalay - $14 \mathrm{~km}$ near Marthandam, immense with dense population and vehicular traffic area.

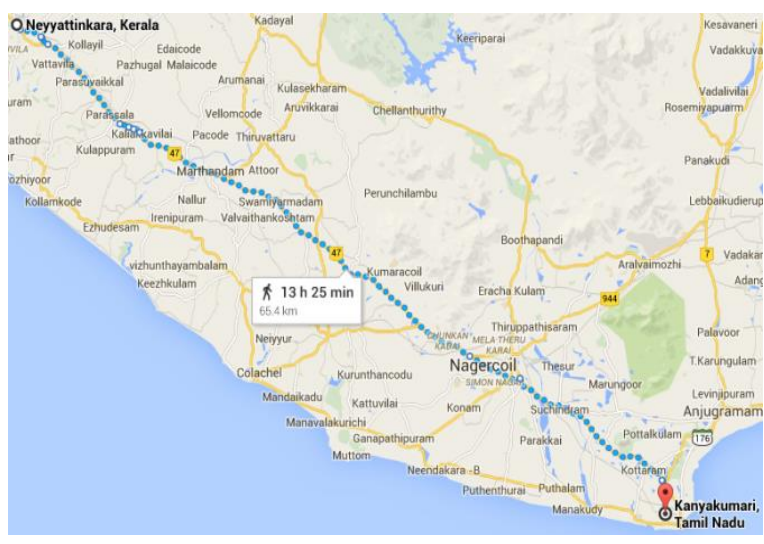

Fig.1: Roadmap of Kanyakumari District. 
- Villukuri - A mountain area exposed to vehicular traffic and located with many Cashew Nut Factories.

- District Nagercoil junction, Nagercoil - Specialized for Latex industry, exposed to vehicular traffic, but with elevated smoke and dust affected area during all seasons.

- Kanyakumari-A tourist area characterized by high wind and seashore exposed to vehicular traffic.

The samples were taken by placing the high volume air sampler at $1 \mathrm{~m}$ above the ground at the following rural locations:

- Colachel Municipality - Known to be densely populated area, coastal and inland areas, Marine and inland fisheries, harvesting, processing, marketing, and distribution, and is characterized by high wind and seashore with dense buildings, narrow streets, and heavy traffic.

- Manavalakurichi - Characterized by ore refining factory (IRE) and seashore exposed to vehicular traffic.

- Monday Market - Known for tiles, brick factories, and cashew nut factories.

- Kurunthencode - Specialized for agriculture located at a distance of $7 \mathrm{kms}$ from Monday Market.

\section{RESULTS AND DISCUSSION}

In general, alpha activity value increases during the winter season. Likewise, in the area of Kanyakumari district, the highest alpha activity value was found during the winter season based on the observations made on two consecutive years between December 2014 and May 2016.

Table 1 summarizes the results obtained from airborne particulate samples. It was observed that the highest and the lowest gross alpha activity values were found in the urban areas of Kanyakumari District based on seasonal variation.
From the overall results obtained in Kanyakumari District, during the winter season, the place Kanyakumari indicates the highest value due to the reason of being a coastal area, which contains a mixture of rare minerals such as garnet, ilmenite, rutile, leucoxene, zircon, sillimanite and monazite. The lowest activity values were found in Thuckalay and Nagercoil during the years 2014 and 2015 due to the absence of the characteristics that relate to alpha activity since those places were meant for high vehicular traffic intensity.

During the summer season of 2014-2016, it is found that the maximum alpha activity value was found in Kanyakumari due to the reason mentioned above. But the minimum activity value was found in the place Thuckalay during the first consecutive year and in the areas such as Kaliyakkavilai, Marthandam, and Nagercoil during the second consecutive year because those areas are not open to the mining process.

Fig. 2 shows the graphical representation of season-based analysis of Alpha Activity in Urban areas of Kanyakumari District. The dark grey line in the figure shows the recorded alpha radioactivity during the winter season and the light grey line represents the recorded alpha radioactivity during the summer season.

The results obtained from airborne particulate samples in the rural areas of Kanyakumari District based on seasonal variation are listed in Table 2. During the winter season, it has been found that the maximum alpha activity value was found in Manavalakurichi for the reason being a coastal area and having refining factories (IRE).

The minimum alpha activity value was found in the $\mathrm{Ku}-$ runthencode area since the area is known for the cultivation of paddy fields and trees like plantain and coconut. Also, the maximum alpha activity value was found in Manava-

Table 1: Alpha activity values in the urban areas of Kanyakumari District.

\begin{tabular}{|c|c|c|c|c|}
\hline \multicolumn{5}{|c|}{ Alpha Activity Values -Urban Area [in Bq.m $\left.{ }^{-3}\right]$} \\
\hline \multirow{2}{*}{ Area / Season } & \multicolumn{2}{|c|}{ Winter Season (Dec, Jan, Feb) } & \multicolumn{2}{|c|}{ Summer Season (Mar, Apr, May) } \\
\hline & 2014-2015 & 2015-2016 & 2014-2015 & 2015-2016 \\
\hline Kaliyakkavilai & 0.000771 & 0.000926 & 0.000617 & 0.000463 \\
\hline Marthandam & 0.000617 & 0.000771 & 0.000463 & 0.000463 \\
\hline Thuckalay & 0.000463 & 0.00108 & 0.000309 & 0.000617 \\
\hline Villukuri & 0.000309 & 0.000771 & 0.000463 & 0.000617 \\
\hline Nagercoil & 0.000617 & 0.000617 & 0.000463 & 0.000463 \\
\hline Kanyakumari & 0.000926 & 0.001234 & 0.000771 & 0.000926 \\
\hline Minimum & 0.000309 & 0.000617 & 0.000309 & 0.000463 \\
\hline Maximum & 0.000926 & 0.001234 & 0.000771 & 0.000926 \\
\hline SD Value & 0.0002334 & 0.000227 & 0.000159 & 0.00018 \\
\hline
\end{tabular}



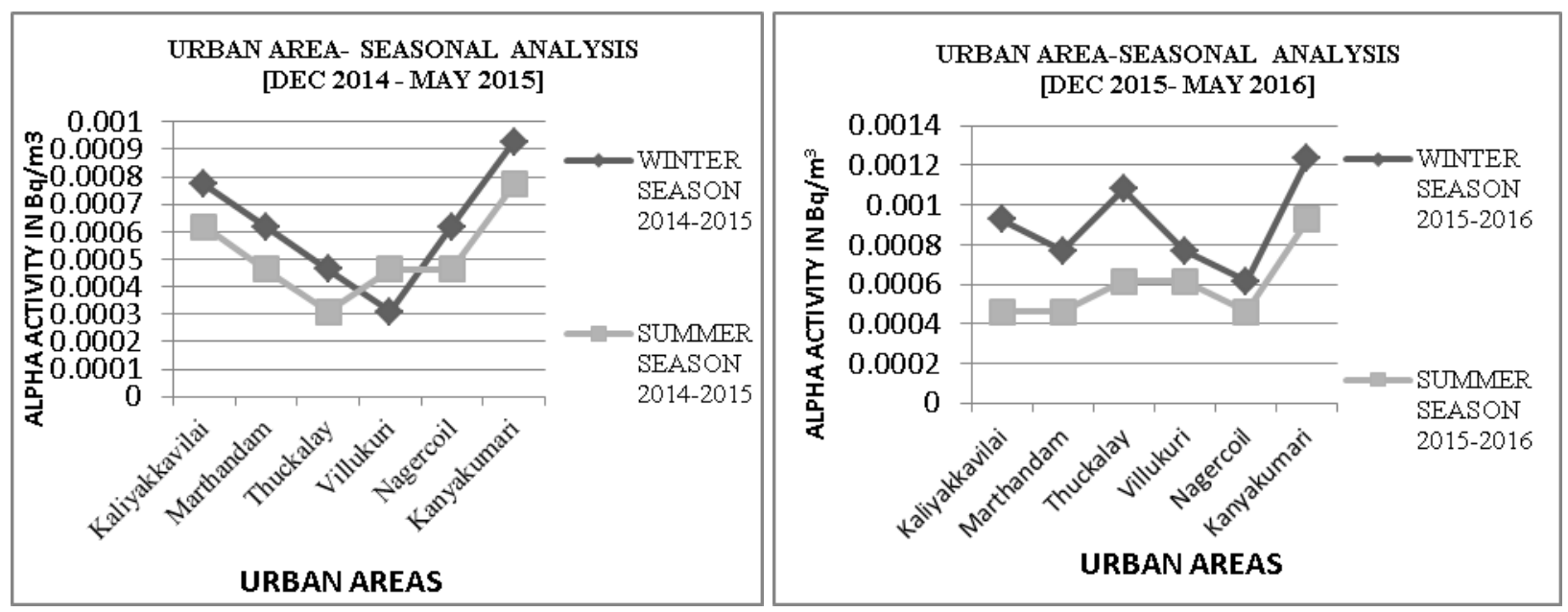

Fig. 2: Season-based analysis of the alpha activity in the urban area.

Table 2: Alpha activity values in the rural area of Kanyakumari District.

\begin{tabular}{|c|c|c|c|c|}
\hline \multirow{3}{*}{ Area / Season } & \multicolumn{4}{|c|}{ Alpha Activity Values -Rural Area [in Bq.m ${ }^{-3}$ ] } \\
\hline & \multicolumn{2}{|c|}{ Winter Season (Dec, Jan, Feb) } & \multicolumn{2}{|c|}{ Summer Season (Mar, Apr, May) } \\
\hline & $2014-2015$ & 2015-2016 & $2014-2015$ & 2015-2016 \\
\hline Colachel & 0.00108 & 0.001234 & 0.000771 & 0.000926 \\
\hline Manavalakurichi & 0.001234 & 0.001388 & 0.000926 & 0.00108 \\
\hline Monday Market & 0.000926 & 0.00108 & 0.000463 & 0.000771 \\
\hline Kurunthencode & 0.000771 & 0.000926 & 0.000309 & 0.000617 \\
\hline MIN & 0.000771 & 0.000926 & 0.000309 & 0.000617 \\
\hline MAX & 0.001234 & 0.001388 & 0.000926 & 0.00108 \\
\hline SD & 0.0001992 & 0.000199 & 0.0002815 & 0.0001993 \\
\hline
\end{tabular}
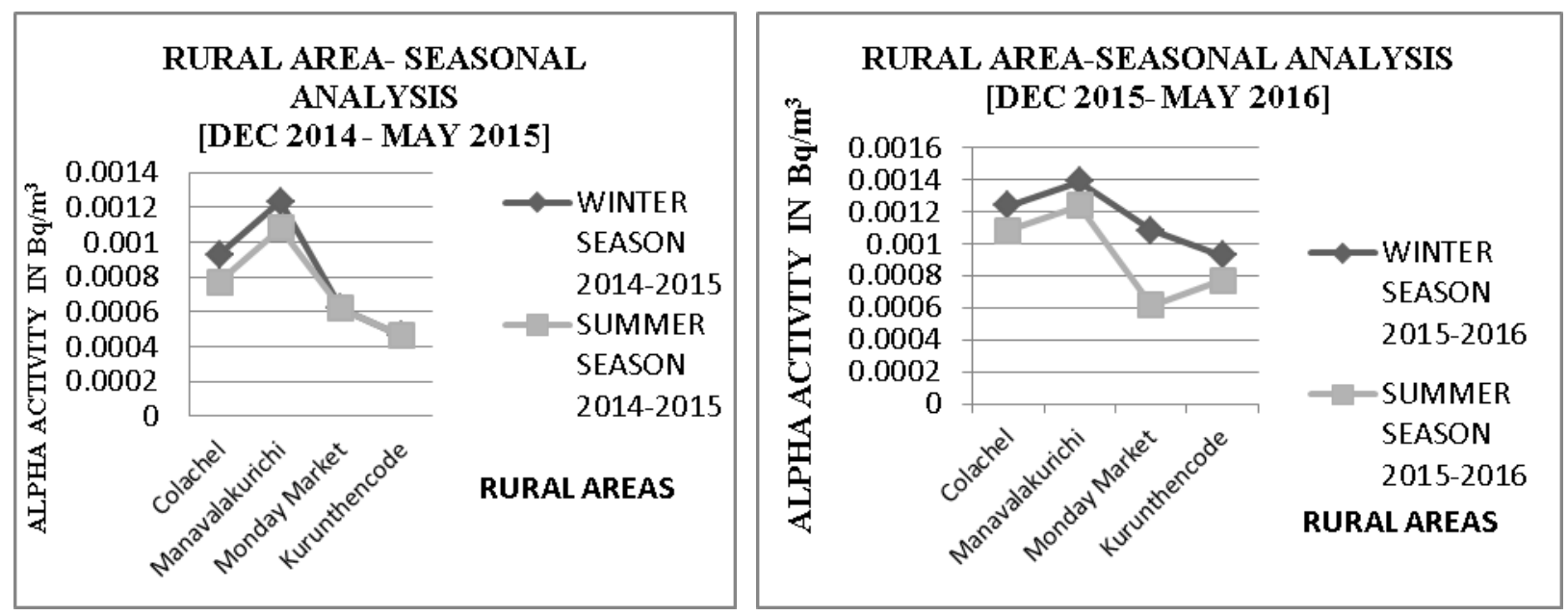

Fig. 3: Season-based analysis of the alpha activity in the rural area. 
lakurichi and the minimum activity value was found in the Kurunthencode due to the reason as mentioned previously.

The graphical representation of season-based analysis of Alpha Activity in rural areas of Kanyakumari District is depicted in Fig. 3. The dark grey line in the figure shows the recorded alpha radioactivity during the winter season and the light grey line represents the recorded alpha radioactivity during the summer season.

So far the findings of both the tables and figures state that the winter season shows the maximum alpha activity value in the air when compared with the summer season, due to the higher rate of sedimentation of Suspended Particulate Matter (SPM) collected from ambient air.

\section{CONCLUSION}

The radioactivity levels of aerosols were studied based season-wise in the urban and rural areas of Kanyakumari district in Tamil Nadu. The gross alpha activities were detected in the collected aerosol samples. The primary conclusion is that sampling locations and particle fractions showed a difference for alpha activity dispersion due to the sources of radioactivity and characteristics of sampling locations. Apart from the above, meteorology plays an important role in the dispersion and transport of radioactivity. To the best of knowledge, the study will be important in the future to use atmospheric activity studies to investigate the influence of the origin of the air masses on concentrations of the gross alpha levels or different radionuclides in the urban and rural areas of the Kanyakumari district. Thus, the analysis made concludes that the alpha activity was found in maximum during the winter season due to the low rate of wind flow in both urban and rural areas.

\section{ACKNOWLEDGEMENT}

We are indebted to the Head, Department of Chemistry, Scott Christian College (Autonomous), Nagercoil for providing the instruments for the collection of the samples and the generous help and permission for using High Volume Air sampler and Nucleonix 605A for analyses of the samples.

\section{REFERENCES}

Arkian, F., Salahinejad, M., Bidokhti, A.A. and Meshkatee, A. 2007. Analysis of gross alpha, gross beta activities and beryllium-7 concentrations in surface air: Their variations and statistical prediction model. Environmental Monitoring and Assessment, 140(1-3): 325-330.

Avwiri, O.G. 2006. Determination of radionuclide levels in soil and water around cement companies in port Harcourt. Journal of Applied Sciences and Environmental Management, 9(3): 26-29.

Roy, S. and Adhikari, G.R. 2009. Seasonal variation in suspended particulate matter vis-a-vis meteorological parameters at Kolar gold fields, India. International Journal of Environmental Engineering, 1(4): 432.

Nakpil, A.S., Baja, E.S. and Medina, P.M.B. 2019. Mutagenicity of bulk, aqueous and organic partitions of air particulate matter in differentially ventilated wards in a public urban hospital. Nat. Env. Poll. Tech., 18(4): 1463-1469.

Samotaev, N., Gurkovskivy, B., Miroshnichenko, V., Onischenko and Simakov, A. 2015. Alpha-radioactive isotopes monitoring of human body contamination by a trace of air ions presence. Procedia Engineering, 120: 874-877.

Songul A., Barbara, K., Anna, W., Ugur, C., Halim, T., Rene, V. G., Lucyna, S. and Ewa, Wi. 2012. Gross alpha and beta activities of airborne particulate samples from Wawel Royal Castle museum in Cracow, Poland. Journal of Radioanalytical and Nuclear Chemistry, 295(2): 1567-1573. 